\title{
Modeling and Simulation of a Single Engine Aircraft Fuel System
}

\author{
Nathan Raphael do Nascimento Pinheiro, and Luiz Carlos Sandoval Góes \\ Engineering Mechanic Department, Instituto Tecnológico de Aeronáutica, São José dos Campos, São Paulo/Brazil \\ E-mail: nathan.raphael@gmail.com, and goes@ita.br
}

\begin{abstract}
The primary function of an aircraft fuel system is to provide a reliable fuel flow at a rate and pressure established for proper engine functioning for each operational condition and aircraft certification requirement. However, to provide fuel flow at a given pressure all sub-functions of the fuel system must work properly simultaneously and integrated as the pressure refueling, quantity gauging, control, and ventilation systems. The present work describes the model creation and simulation for aircraft fuel system during pressure refueling and single engine operation. Since the fuel system is composed of several subsystems highly integrated to each other, the proper functioning of the fuel system depends on this integration and a literature review was accomplished in order to raise the required information regarding sub-functions integration to create the model in LMS Amesim ${ }^{\circledR}$. The LMS Amesim ${ }^{\circledR}$ model created to represent the existing correlations between each sub-system was simulated for pressure refueling and engine operations. Finally, the result of model simulation shows the functioning of the fuel system for normal operational conditions in conjunction with its sub-systems.
\end{abstract}

Keywords: Modeling, simulation, aircraft, fuel, system

\section{Introduction}

The primary function of an aircraft fuel system is to provide a reliable fuel flow at a rate and pressure established for proper engine functioning for each operational condition and aircraft certification requirement. Without the constant fuel supply (within the proper limits) the motive thrust provided by the engine could be compromised as well as aircraft ability to sustain flight. Thus, the fuel system shows itself as essential for a safe flight and mission accomplishment [1].

Other functions of the fuel system in modern aircraft are given by the close relation between overall systems performance as shown in fig. 1 . The fuel system can interfere in the aircraft performance by moving the CG positioning thus changing flight control stability margins. The fuel can be used as heat sink for systems with high rates of heat generation, or even as hydraulic fluid [2] for example in case of the Lockheed SR-71 Blackbird fuel valves located close to the afterburner [3].

The fuel system is composed of several subsystems to comply with the functions required by the propulsion system. In this way, the system is divided in the following subsystems: engine feed, fuel storage, refuel and defuel, fuel transfer, engine feed line fuel pressurization, vent systems, fuel jettison, in-flight refueling, and others. The proper functioning of the fuel system depends on the performance and integration of the aforementioned subsystems, for this reason some of them, depending on the aircraft missions, must be tested to guarantee its integration [4].

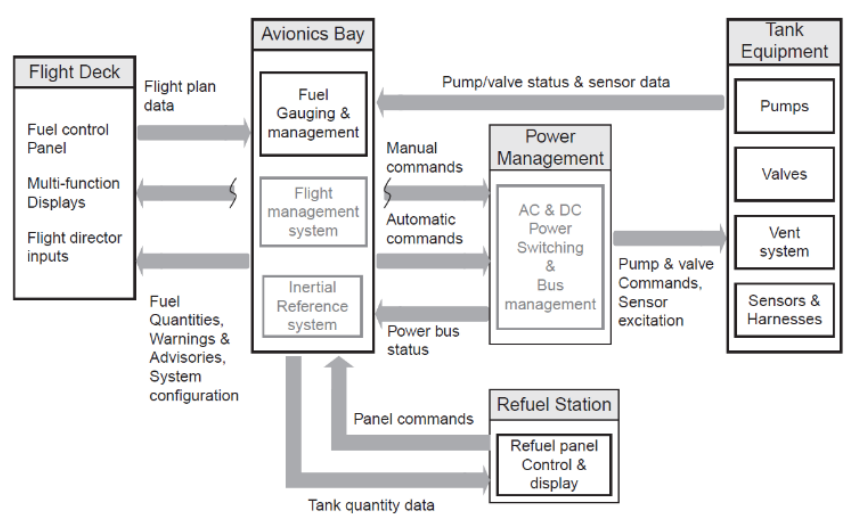

Figure 1: Fuel system typical schematic [1]

The work presented herein aims to model and simulate the fuel system of a single engine aircraft to determine the behavior of the entirely system by the simultaneous and integrated simulation of it sub functions. The fuel system architecture chosen for the simulation is based on military aircraft applications in order to represent specific operational conditions and restrictions, as the use of a main tank which needs to be completely full during operation. The focus of this work is to model and simulate an aircraft fuel system for refueling and defueling operations, and also pressurization of engine feed line. All system models are implemented in LMS Amesim ${ }^{\circledR}$. The main components 
behavior is presented in graphs to validate the hypotheses made and requirements to modeled system.

The LMS Amesim ${ }^{\circledR}$ is a multi-physics model and simulation software where different domains can be integrated and analyzed simultaneously. In addition it has specific aerospace libraries such as the fuel system library which presents already implemented application as gaging system and fuel tank models. The LMS Amesim ${ }^{\circledR}$ was chosen for this analysis because of the already modeled components and the capability of integrating different domains in the same model.

\section{Modeling and Simulation}

The modeling process adopted for this work consists of identifying the fuel system functions to be tested, the components used to perform system functions, and fuel properties. Therefore a specific fuel system was chosen based on the real application and also to represent the aspects related to a generic aircraft fuel system model presented in fig.2. The fuel system model was developed with LMS Amesim®. The hypotheses and simplifications applied to fuel system model adopted for analysis, as well as generic parameters used to represent real components will be described in next sections.

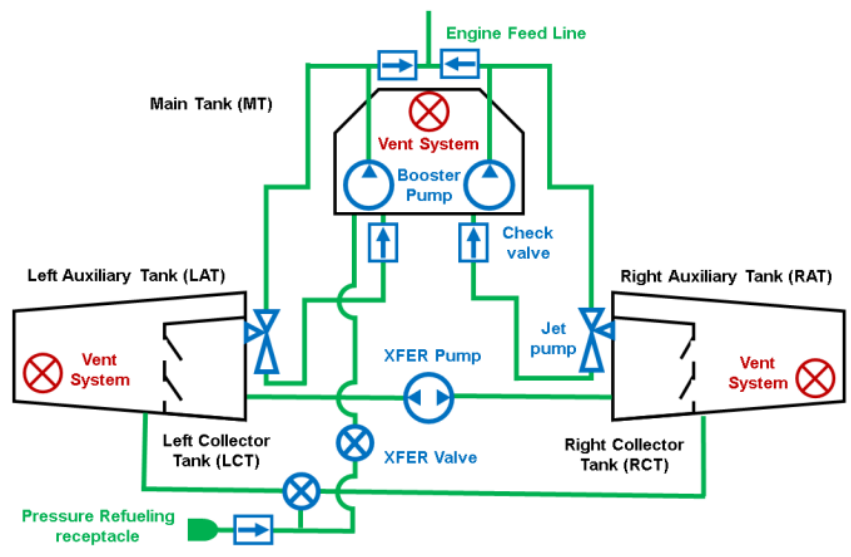

Figure 2: Fuel system adopted for analysis

In the modeling process adopted for this work, Jet A-1is considered as the fuel reference for all analysis. As Jet A-1 is widely used for jet turbine and its properties are well known for the range analysis, all simulations shown in this section were developed using Jet A-1 properties.

There are a series of limitations imposed by the assumptions made on LMS Amesim ${ }^{\circledR}$ libraries that work for fuel system simulation as fundamental hypotheses. These simplification hypotheses are listed below:

- The liquid temperature is homogeneous within the tank;

- The gas temperature is homogeneous within the tank;

- The fuel inertia is not considered while analyzing fuel accelerations effect, thus slosh is not accounted for in the presented analysis;
- The reference frame definition is fixed, that is why the tank has a one meter cubic form;

- The composition of the gas in the tank is not affected by the fuel pressure and temperature state;

- Wall orifices are circular.

As the right and left tanks have the same characteristics, components and functions, in this work it was used only the left and collector tank to represent the entirely system. Therefore the lack of information regarding right wing tank functioning, the left wing tank in addition with the collector tank present enough information about the functions to be tested regarding the completely system, thus saving computational effort.

As the collector tank has the purpose of providing fuel flow at pressure and flow rate established by engine fuel consumption during aircraft operation, it is very important to have this tank full whenever it is possible [5]. To guarantee that the collector tank will be full whenever the system has enough fuel to accomplish it, this tank will be the first to be refueled and the last tank to sold out during engine operation.

The block diagram presented in fig. 3 represents the fuel system architecture chosen for analysis and presented in fig.2. To represent all existing components in the metaphysics simulation, the following libraries were chosen from LMS Amesim ${ }^{\circledR}$ category path list: Aircraft Fuel System, Signal, Control, Mechanical, Hydraulic, Pneumatic, Thermal, Thermal Hydraulic, and Aeronautics \& Space. In this way all the components needed to represent the system architecture in fig. 2 were modeled in fig. 3 for the fuel system simulation.

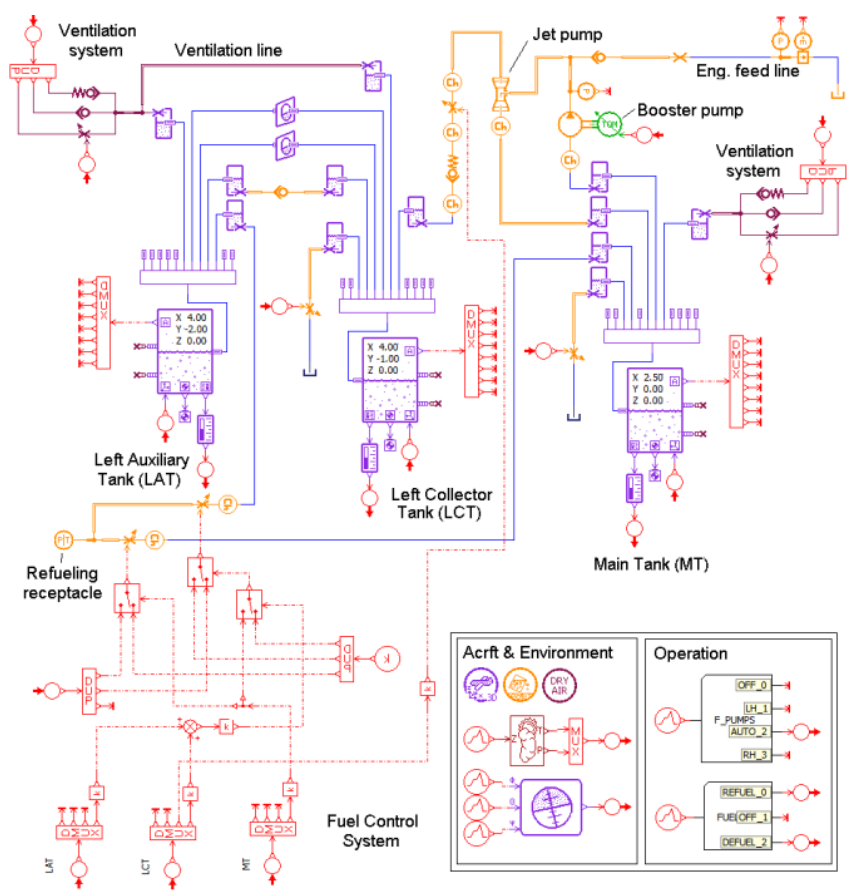

Figure 3: Fuel system model in LMS Amesim ${ }^{\circledR}$

To run the presented fuel system model on LMS Amesim® the program configuration chosen is a standard integrator with a tolerance of 10-6. 


\section{Results}

The fuel system functions are highly integrated. The ventilation, gauging, and management systems work in parallel with the refueling, defueling, engine feed line, and transfer fuel system. For this reason the simulation results presented in this section corresponds to the fuel system simulation as a whole. In the fig. 4 and fig. 5 it is presented the parameters chosen to validate that the subsystems are working properly to guarantee that all fuel system functions are performed correctly. Time slices are shown to analyze specific functions or operational procedures.

The operation of the refueling system requires an interaction between the aircraft and ground service team or flight crew. In the figures presented herein these interfaces are represented as signal controls. During the simulation time, the main signal controls are shown to exemplify the actuation of two operational procedures: refueling and fuel pumps activation. In fig. 4 it is shown the signal controls for the simulation model.

Firstly, the refueling signal, generally given by the ground service team, shows that the refueling operation is performed from 0 seconds until instant 800 seconds. During this time defueling signal and fuel pump electrical signal are not activated. After the completion of fuel tanks the fuel pump is activated at instant 900 seconds and the fuel is pressurized through the engine feed line until the end of simulation at instant 46,886 seconds.

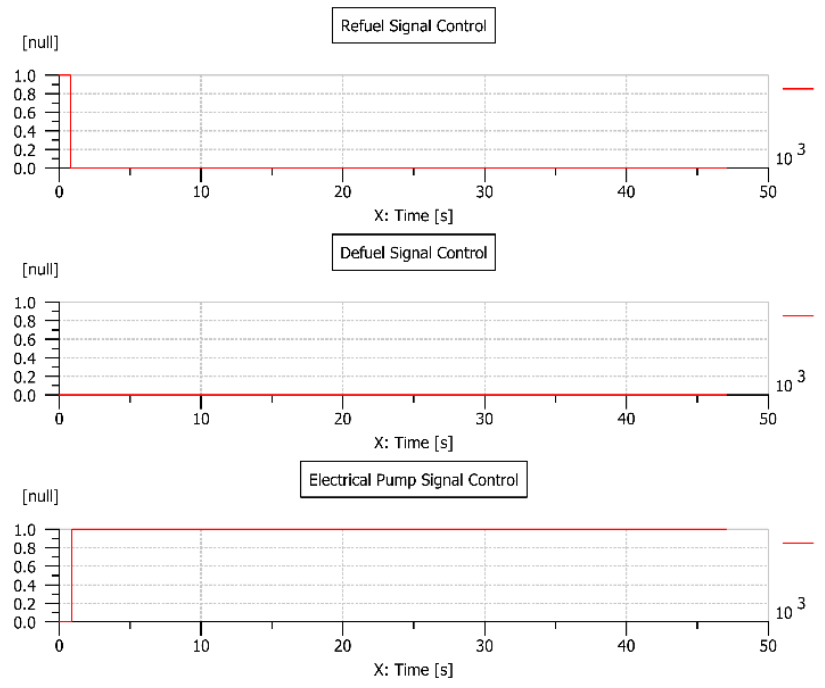

Figure 4: Signal control

The fuel tanks dimensions adopted for the simulation are cubes of one meter edge size only to simplify the gauging system. The gauging system is composed of fuel probes which inform the fuel level stored in each tank. The indication of zero meters means that there is no fuel stored, and one meter means that there is one cubic meter of fuel stored, i.e. the fuel tank is completely full. Therefore, the value presented by the fuel gauging system can be interpreted as tank percentage completion.

In fig.5 it is shown fuel tank levels in meters during the entire operation. The first graph shows the main tank (MT) level responsible to provide fuel to the engine feed line, the second shows the left collector tank (LCT) level designed to collect all fuel from the left auxiliary tank and transfer it to the main tank, and the third graph presents the left auxiliary tank (LAT) designed to store fuel. These three tanks (MT, LCT and LAT) are presented in fig. 3 .

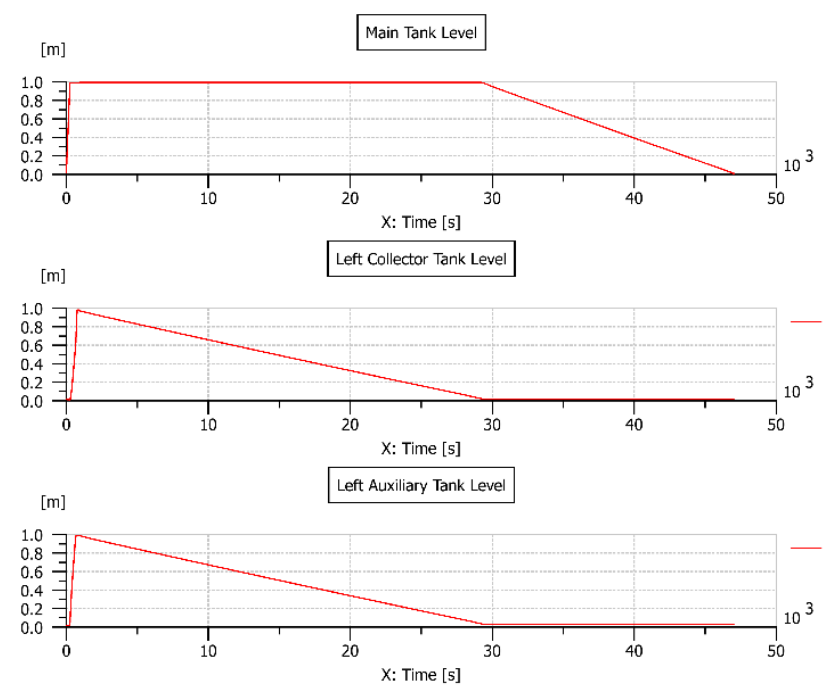

Figure 5: Tanks level during system fuel system operation

As shown in the system architecture in fig. 2 and model in fig.3, there is one main liquid communication between the left auxiliary tank and the left collector tank which is the flapper valve. There are also two holes that connect one tank to another, one hole is located in the bottom of the tanks and the other in the top. Once the left auxiliary tank is refueled and the liquid level reaches a minimum height to pressurize the check valve, the check valve opens to allow fuel flow from the outer to the inner wing tank. In fig. 6 it is shown that once the left auxiliary tank level increases, the fuel flow in the check valve also increases until the end of the fuel transference between tanks. Once the left collector tank is fully refueled there is no pressure differential, so there is no more fuel flow through the check valve.

At the instant $650 \mathrm{sec}$ shown in fig.6, the upper hole that connects both tanks (as shown in fig.3) is closed. As the pressure inside the left auxiliary tank increases because of the fuel level, the fuel flow rate through the check valve also increases. Then, at instant $675 \mathrm{sec}$ the left auxiliary tank is completely refueled, as shown in fig.6 in the first chart. As the duel flow is constant during tanks refueling, and the left auxiliary tank is already fulfilled, the fuel flow rate for the remaining tank increases, as shown in fig. 6 in the second chart, instant $675 \mathrm{sec}$. 


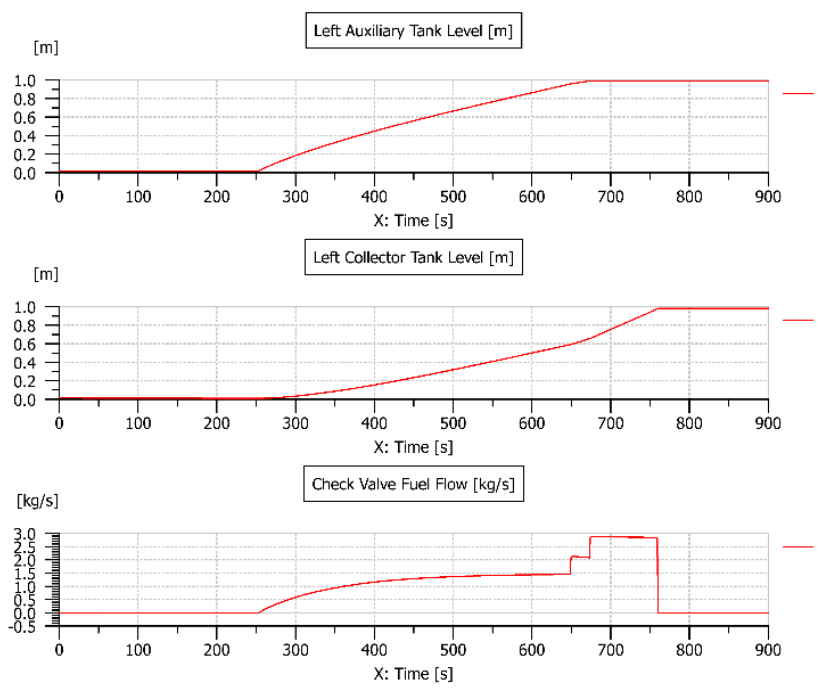

Figure 6: Tanks level and check valve fuel flow

To guarantee that the fuel tank is completely refueled at the time needed using the pressure refueling system and without causing any structural damage to the aircraft, it is necessary to permit that the volume of air stocked in the tanks gets to the atmosphere [6]. For this reason vent valves with relatively high admissible flow rates are opened by the same refueling signal. Thus the air stored in the tanks is removed while tanks are refueled.

Because of the fuel system architecture adopted for the analysis and also because of the tank refueling sequence, while the main tank is refueled, the volume of air remaining in the tank is expelled through the venting system at the same rate the tank is refueled as suggested by graphs in fig.7. The negatives values shown in the second row indicates that the fuel is getting in to the fuel tanks. Since the left auxiliary and collector tank ventilation system are the same, the collector tank ventilates through the auxiliary tank.

From instant 0 to $250 \mathrm{sec}$ in the third chart of fig.7, as the main tank is refueled, the maximum air flow through the ventilation port is observed. From instant $250 \mathrm{sec}$ to $650 \mathrm{sec}$, the left auxiliary and collector tanks are refueled. As the refueling point is located in the left auxiliary tank, the auxiliary tank is refueled faster than the collector tank. For this reason the air flow through its ventilation port is higher than in the auxiliary tank. However, the sum of air flow measured in both wing tanks has the same magnitude as the flow measured between instants 0 to $250 \mathrm{sec}$ in the main tank.

At instant $650 \mathrm{sec}$ in fig.7, the fuel level reaches the ventilation hole located in the upper part of the wing tanks. As the auxiliary tank is already full, and the ventilation hole internal outlet is below the fuel level, the air flow stops in the auxiliary tank ventilation port. As mentioned before, once the auxiliary tank is refueled, all the fuel flow once divided by the two tanks is directly transferred to the left collector tank. For this reason, after instant $650 \mathrm{sec}$, the fuel level in the left collector tank increases in a higher rate compared to instant $250 \mathrm{sec}$ to $650 \mathrm{sec}$. As the refueling ratio increases, the air flow through the ventilation system also increases from $650 \mathrm{sec}$ to $760 \mathrm{sec}$, shown in the third chart of fig. 7 .

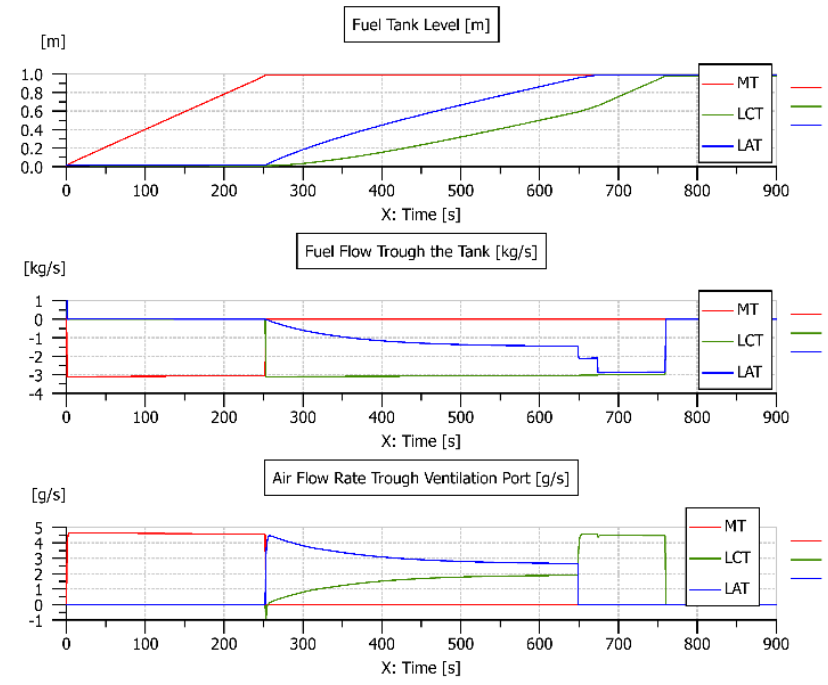

Figure 7: Ventilation system operating during refueling

The most important function of the fuel system is to feed the engine in any point of the aircraft flight envelope [5]. So in order to avoid fuel starvation, the situation where the aircraft has fuel but cannot provide it at require flow rate and pressure to the engine, the fuel feed line is in many applications pressurized by booster pumps. In this simulation, a flow rate of $150 \mathrm{~kg} / \mathrm{h}$ and line pressurization of at least 6 psi adopted to guarantee that the engine will receive the quantity of fuel needed for operation without cavitation in the feed line. The engine's manufacturer recommends an overpressure of 2 psi above fuel vapor pressure in the worst envelope condition, and the maximum fuel flow must be determined according to the maximum engine consumption.

The fig. 8 shows the main parameters related to engine feed line pressurization during engine operation. The first chart shows the fuel pump control signal used to actuate the electrical pumps, in this case booster pumps. The fuel pump is actuated just before tank refueling from instant 900 seconds until the end of simulation. The second chart presents the fuel pressure provided by the booster pumps to the engine feed line. In this case the pressure is measured upstream to the check valve for engine feed line pressure monitoring. The fuel pump parameters for analyses were chosen to guarantee that the pressure in the fuel line remains at least at 6 psi, however, according to simulation results, the minimum pressure during aircraft operation is 8.7 psi. The third chart shows the fuel flow through the check valve during simulation. From instant 900 seconds to the end of the simulation, the lowest registered flow rate is $152 \mathrm{~kg} / \mathrm{h}$. Finally, the fourth chart shows the fuel tank level decreasing while the engine is operating. Because of the fuel system architecture adopted for the analyses, the booster pump pressurizes the engine feed line and the jet pump. Therefore fuel is transferred from the left auxiliary to collector tank by the jet pump. Once there is no more fuel in the wing tanks (left auxiliary and collector tanks), the fuel volume in the 
main tank decreases and then pressure inside the tank drops until the vent valve reacts opening the check valve to allow air to come into the main tank. For this reason a step is observed in the pressure and fuel flow rates curves (second and third charts) when the wing tanks are just empty.

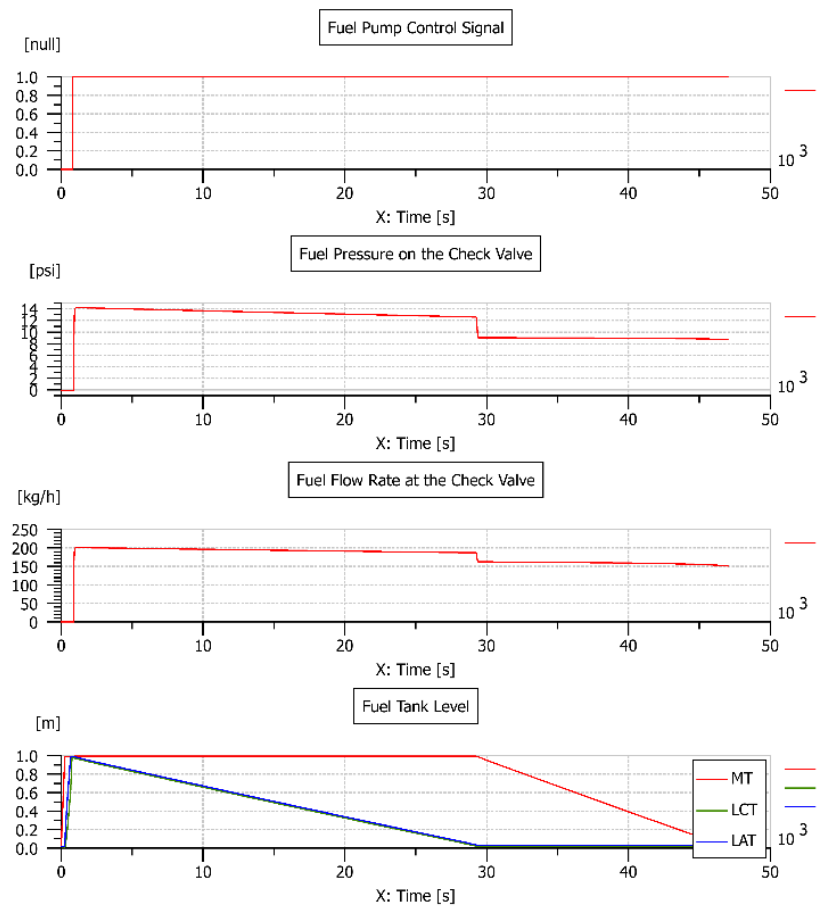

Figure 8: Engine feed line pressurization

\section{Conclusions}

In the work presented herein aspects of correlation between the fuel system sub-functions, and their integration were studied using simulation. For the two operations simulated, refueling and engine feed line pressurization, the interactive behavior of gaging, ventilation, management, transfer, and refueling subsystems was observed.

For the refueling operations simulation results shown that while the main tank is refueled, an induced air flow proportional to the refueling rate is observed in the ventilation system. As the flow rate remains the same during wing tanks refueling, the sum of the air flow from both wing tanks exhausted by the ventilation system is the same observed in the main tank. This behavior is similar to the one observed in real aircraft.

Also for the refueling operations, the gaging system actuates the shut-off valves to guarantee that the aircraft tanks will be refueled in the correct sequence. As the operation starts, the shut-off valve is opened while the valve located in the left auxiliary tank remains closed. Once the main tank is refueled, through the management system actuation, the shut-off valve located in the left auxiliary tank opens through the management system actuation, based on the information provided by the gaging system. Finally, the refueling operation is interrupted when the gaging system identifies that all tanks have been fully refueled. A signal control is sent to the management system that actuates the shut-off valves and finalizes the operation as shown in fig.4, as in a real aircraft normal operation.

For the engine feed line pressurization operation the fuel pump actuates pressurizing the engine feed line for a given pressure. The pump is commanded through an electrical motor which provides torque to the fuel pump. The engine feed pressurization provide the required pressure and fuel flow rate to the ejector pump, thus transferring fuel from the left collector tank to the main tank. During engine feed line pressurization, while there is usable fuel in the wing tanks, the fuel level is not affected. Only after all the fuel is exhausted from the wing tanks the main tank fuel level is affected. During the fuel transference from left collector tank to the main tank, the fuel level from the collector tank decreases causing a pressure differential between it and the left auxiliary tank. Because of this pressure differential the fuel level is gravitationally transferred from the auxiliary to the collector tank, as shown in fig.6. For both cases the transfer fuel system operates properly as in a real setup, the flapper valve opens due to a fuel level difference and the fuel is transferred through the ejector pump to the main tank.

During wing tank refueling, as shown in fig.7, three steps in the air flow curve were observed in the ventilation system. The steps are related to the refueling rate of each tank. At the first instants of operation both tanks have the same fuel level, when the fuel level in the left auxiliary tank reaches the ventilation hole between the two wing tanks, as the left auxiliary tank is almost full and ventilation area is reduced, the fuel flow to the left collector tank increases. For this reason the air flow instantly steps up. When the auxiliary tank is completely full and all the fuel transferred to the aircraft is directly refueled in the left collector tank, the fuel flow increases again, leading the ventilation flow to a higher step. In this case, the ventilation system works to relief the excess of pressure in the fuel tanks. The air flow through the ventilation system is proportional to the refueling ratio, as observed in real aircraft operation.

Therefore, in this study, modeling and simulation of a single engine aircraft fuel system, regarding refueling operations and pressurizing of the engine feed line, was accomplished through the model presented in fig.3. The fuel system architecture chosen for the simulation was based on military aircraft applications in order to represent specific operational conditions and restrictions, for example the capability to perform aerobatic maneuvers due to the existence of a full collector tank. The fuel system sub functions as ventilation, fuel quantity gauging, and fuel management control were implemented in the model and the results show the integrated functioning of all sub-functions to accomplishment of fuel system main functions.

The main conclusion is that the modelling and simulation approach can be applied to determine fuel system behavior during early development project phases. For example, the model can be adapted and used to determine the number of fuel pumps in the fuel tanks to provide adequate fuel flow to the engine, and also to actively control aircraft center of gravity via transferring of fuel between tanks. Another example is the study of best location of fuel probe gages 
best for optimal accuracy. The work can also be used in model-based system design processes to foresee system solutions and issues during product development phases. The simulation can provide reliable information to decision making process. The process adopted herein is also applicable to existing aircraft aiding in troubleshooting investigations, gaging systems studies, ventilation system dimensioning, and fuel management system tests.

\section{References}

[1] MOIR, I.; SEABRIDGE, A. Aircraft System. Third. [S.1.]: John Wiley, 2008.

[2] LANGTON, R.; CLARK, C.; HEWITT, M.; RICHARDS, L. Aircraft Fuel System. First. [S.1.]: John Wiley, 2009.

[3] SR-71A Flight Manual. [S.1.]. Section I, page 4. 2016. <http://www.sr-71.org/> Acessed on 2016-12-13 at 20 p.m.

[4] MIHALYI, L. Multi Objective Optimization and Probabilistic Design on Aircraft Fuel System. Master's Thesis. Luleå University of Technology, 2007.

[5] GAVEL, H. On Aircraft Fuel System Conceptual Design and Modeling. Dissertation. Linköpings Universitet, 2007.

[6] MOIR, I.; SEABRIDGE, A. Design and Development of Aircraft System. [S.1.]: John Wiley, 2013. 